\title{
O IMPACTO DO PROGRAMA “LEITE NOTA Io" NA ATIVIDADE LEITEIRA PARA AS MULHERES AGRICULTORAS DO MUNICÍPIO DE DOUTOR MAURICIO CARDOSO- RS
}

\author{
Darlan Fronza ${ }^{1}$ \\ Guilherme Marusak Tura ${ }^{2}$ \\ Jaqueline Raquel Nagel ${ }^{3}$ \\ Luciano Rafael Zirr ${ }^{4}$ \\ Ivar José Kreutz ${ }^{5}$
}

RESUMO: Este trabalho teve como objetivo avaliar se o programa "leite nota ıo" tem alcançado os objetivos de real satisfação entre os beneficiários. A busca por resultados deu-se através da aplicação de questionário para uma amostra da população de produtoras rurais participantes do programa, das localidades de Vila Pitanga e Lajeado Guabiroba do Município de Doutor Maurício Cardoso. O programa possui uma política de grande importância para incentivar a permanência nas propriedades, pois incrementa a renda dos produtores no final de cada trimestre. São realizadas reuniões técnicas para distribuição dos bônus e qualificação técnica. Um dos requisitos para ter direito ao benefício é ter pelo menos uma nota fiscal trimestral para comprovar a venda do leite.

Palavras- chave: Qualificação. Benefícios. Produção leiteira.

\section{INTRODUÇÃO}

O leite é uma moeda de fundamental importância no mercado de Doutor Mauricio Cardoso. O município é constituído por médias e pequenas propriedades, que muitas vezes tem sua renda dependente da atividade leiteira. Com base nestes dados foi criado o programa "leite nota ıo", que tem por intuito beneficiar e capacitar mulheres produtoras de leite do município.

De acordo com a Lei Municipal no $1591 / 2011$, que revoga na íntegra as Leis Municipais n $1096 / 06$ de 20 de abril de 2006 e n 1228/o7 de 28 de dezembro de 2007, o incentivo para as mulheres se dá em forma de bônus em alguns serviços necessários para a produção, como a inseminação artificial em bovinos de leite, e

${ }^{\text {I }}$ Acadêmico, Faculdade de Agronomia da SETREM, Três de Maio, RS.

${ }^{2}$ Acadêmico, Faculdade de Agronomia da SETREM, Três de Maio, RS.

${ }^{3}$ Acadêmico, Faculdade de Agronomia da SETREM, Três de Maio, RS.

${ }^{4}$ Acadêmico, Faculdade de Agronomia da SETREM, Três de Maio, RS.

${ }^{5}$ i Engo Agro Dr., Professor, Faculdade de Agronomia da SETREM, Três de Maio, RS. 
também em forma de moeda por litro de leite produzido, que é distribuído trimestralmente. Além disso, é oferecida assistência técnica, através de orientação no dia a dia da propriedade, que visa melhor formação e produção do rebanho leiteiro.

Conforme o projeto leite nota 10, com o aumento tecnológico no campo se faz necessário a adoção de mecanismos de aprendizagem e capacitação de produtores rurais, um fator que vem sendo limitante a muitos produtores rurais. A capacitação busca promover autonomia econômica das mulheres produtoras rurais, considerando pequenas e médias propriedades, principalmente onde há dificuldades de capacitação, estruturas, serviços, custeios e equipamentos que são fundamentais para o desenvolvimento rentável da propriedade.

Com base nas questões histórico culturais, por muitos anos as mulheres não eram consideradas trabalhadoras rurais, sendo que ocupavam um grande papel na agricultura. Além de cuidar da casa tinham tarefas no campo, tendo uma grande importância no papel socioeconômico. Segundo Deere (2004), os direitos formais das mulheres à terra somente foram conquistados a partir da criação Constituição de 1988. Com uma boa política de incentivo à produção leiteira é possível ver um ótimo desenvolvimento da atividade. Pode-se observar que o município de Doutor Maurício Cardoso, através da Lei Municipal, incentiva a produção de diferentes maneiras, seja na questão zootécnica, seja introduzindo genética de qualidade nas propriedades, através de subsídios na inseminação artificial e ainda com capacitação técnica aos produtores, qualificando e modernizando as propriedades rurais.

$\mathrm{O}$ artigo $\mathrm{I}^{\circ}$ da Lei Municipal no I59I/20II "institui bônus de incentivo a inseminação artificial ao rebanho leiteiro e concede bônus de incentivo a comercialização formal ao litro de leite", favorecendo e igualando a distribuição do benefício.

\section{OBJETIVOS}

O presente estudo teve por objetivo avaliar se a capacitação do programa "Leite nota ıo" tem sido alcançado de forma satisfatória entre as beneficiárias. 
Os objetivos específico são descritos da seguinte forma:

- Verificar se está havendo a correta aplicação dos insumos disponibilizados;

- Identificar a satisfação entre o público alvo do projeto;

- Diagnosticar o número de mulheres participantes nos cursos de capacitação proporcionados no projeto;

\section{METODOLOGIA}

O primeiro procedimento efetuado neste trabalho foi a delimitação do tema a ser estudado, para posteriormente a elaboração de um questionário com cinco perguntas alternativas, em que avaliam o real conhecimento das mulheres produtoras rurais sobre a execução do programa nas propriedades. A pesquisa foi realizada no dia 04 de novembro e abrangeu is mulheres produtoras rurais nas localidades de Vila Pitanga e Lajeado Guabiroba.

O procedimento utilizado é o estudo de acaso, sendo que a coleta de dados foi efetuada na forma de entrevista formal, onde o entrevistado responde às perguntas de acordo com seu conhecimento do programa.

\section{ANÁlISE E DISCUSSÃO DOS RESULTADOS}

O setor leiteiro é considerado o mais frágil entre os setores, pois é formado por grande parte de pequenos produtores, não organizados e distribuídos por todo território nacional. "A região noroeste do Rio Grande do Sul é o principal polo de produção de leite do Estado, o segundo maior produtor do país” (EMBRAPA PECUÁRIA SUL, 2010).

O programa leite nota io atualmente conta com 147 produtores atuantes e participantes, quem tem direito de receber o benefício no valor de o,oo6 centavos de reais por litro de leite comercializado, tendo que comprovar através de nota fiscal a comercialização do mesmo, sendo pago trimestralmente para as mulheres.

Para que ocorra a permanência das propriedades é bonificado também o valor das inseminações no valor de $\mathrm{R} \$ 50,00$ e é preciso de que cada produtor tenha no mínimo 4 vacas em lactação. O produtor cadastrado no programa também terá direito ao desconto de $75 \%$ no custo da hora máquina, e gratuitamente a limpeza de 
silos e bebedouros um grande suporte necessário nas atividades diárias.

Segundo PROJETO LEITE NOTA io, além de políticas de incentivo de distribuição de bônus, está previsto também que cada produtora receba visitas técnicas periódicas para auxiliar em suas atividades, como formação de pastagens, conservação de solos e saúde do rebanho leiteiro. A partir disso formulou-se a seguinte questão: $O$ programa leite nota io lhe proporciona visitas técnicas periódicas, recomendando e auxiliando na produção leiteira?

Gráfico I- Exemplificando a ocorrência de visitas técnicas

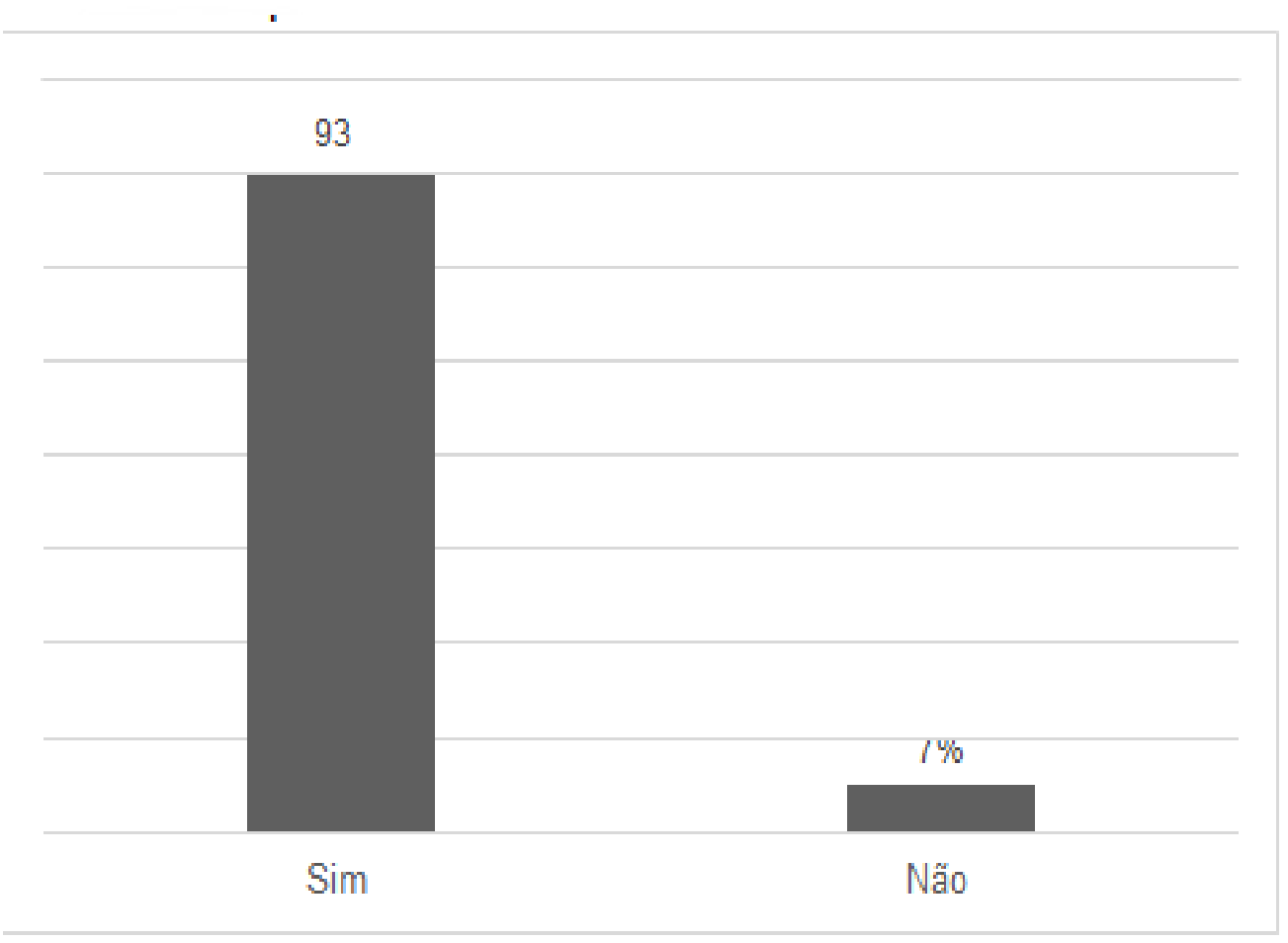

Fonte: FRONZA, TURA, NAGEL, ZIRR (2017)

O gráfico I demostra que a maioria, cerca de $93 \%$, disse que recebe orientações técnicas necessárias e apenas $7 \%$ disse que não recebe, mostrando assim que o programa realmente está sendo executado com efetividade neste quesito de fundamental importância. Também de acordo com relatos das entrevistadas, as propriedades que estão com sua produção abaixo de io litros/dia/vaca, estão recebendo visitas mais frequentes. A Prefeitura Municipal incentiva uma maior produtividade e consequentemente uma maior rentabilidade de suas propriedades, evitando assim a desistência do setor leiteiro. 
Gráfico 02- Demostra a qualidade técnica dos profissionais que atendem as propriedades.

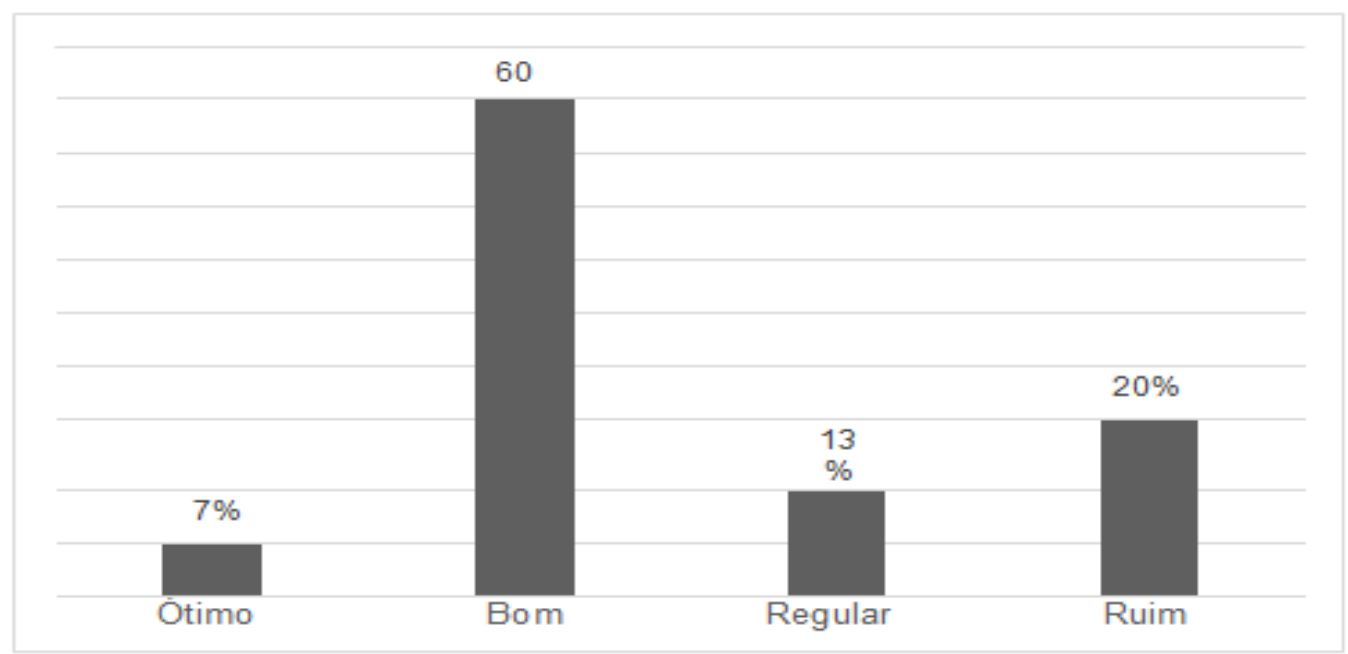

Fonte: FRONZA, Darlan; TURA, Guilherme; DEMBOGURSKI, Miguel (2017)

Conforme apresentado no gráfico 02, é notável que os profissionais responsáveis pela assistência técnica necessária são de boa qualidade, pois nas entrevistas realizadas alegou-se que $60 \%$ dos profissionais tem capacidade compatível com a exigência do programa, porém apenas $20 \%$ considera a qualificação dos profissionais como ruim.

Gráfico 03- Demonstra a satisfação das produtoras em relação ao programa.

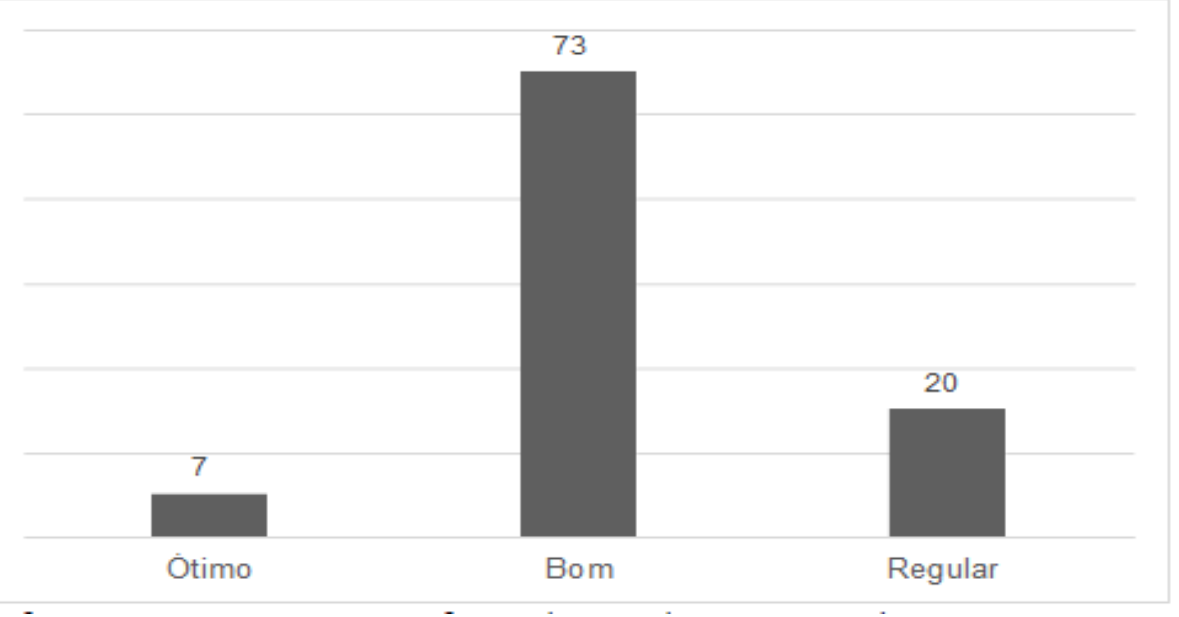

Fonte: FRONZA, TURA, NAGEL, ZIRR (2017)

Como é expresso no gráfico 03 , há uma grande satisfação por parte das produtoras em relação ao programa leite nota io, mostrando que mais de $70 \%$ das mulheres entrevistadas disseram que o programa é bom e traz benefícios. Percebe- 
se grande satisfação e reconhecimento, não tendo nenhuma resposta negativa ao programa, mostrando que está acontecendo tudo conforme descrito na Lei Municipal no 1591/2011.

Gráfico 04- Neste gráfico ilustra a frequência dos cursos promovidos.

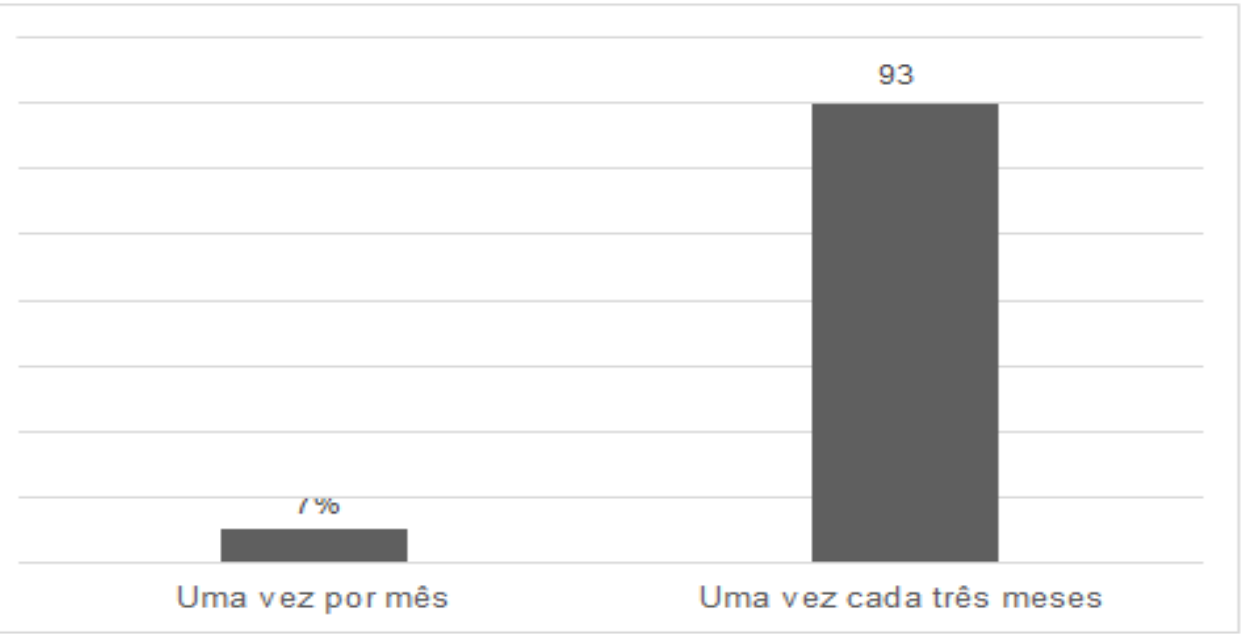

Fonte: FRONZA, TURA, NAGEL, ZIRR (2017)

O gráfico 04 demostra que realmente estão acontecendo cursos de capacitação e incentivo à produção, pois $93 \%$ das entrevistadas responderam que o curso está acontecendo trimestralmente, conforme previsto em lei. Com isso pode-se observar que o programa leite nota io tem um cronograma ocorrendo corretamente.

\section{CONCLUSÃO}

A partir dos dados obtidos, podemos concluir que a eficiência do programa leite nota io no Município de doutor Mauricio Cardoso é satisfatória e a qualificação dos profissionais é considerada boa pela maior parte das entrevistadas, confirmando a primeira hipótese.

A segunda hipótese também acabou sendo confirmada, pois observa-se queo programa atinge a maioria das propriedades, mesmo a participação sendo de livre escolha de cada produtor.

Portanto é possível afirmar que o programa leite nota io tem efetividade, atingindo o público alvo desejável, que são as mulheres produtoras, e trazendo uma série de benefícios auxiliando uma melhor produção e a busca constante por melhores resultados. 


\section{REFERÊNCIAS}

AMBROZIO, Antônio Marcos Hoelz. 2013. BNDS Setorial 38. In: GUIMARRÃES, Diego; CAPANEMA, Luciana; FREIRE, Jaldir; JUNIOR, Celso de Jesus; SILVA, Marco Antonio; SIDÔNIO, Luiza. 2013. Analise de experiências internacionais e propostas para o desenvolvimento da cadeia produtiva brasileira do leite. Revista BNDS Setorial. V. 38. Rio de Janeiro: BNDS. p.5-54.

DEERE, Carmen Diana. 2004. Os direitos da mulher à terra e os movimentos sociais rurais na reforma agrária brasileira. Rev. Estud. Fem., Florianópolis, v. I2, n. I, p. 175-204, abr. 2004 . Disponível em: <http://www.scielo.br/scielo.php? script=sci_arttext\&pid=Soro4 026X200400oroooro\&lng =pt\&nrm=iso $>$. Acesso em I5/II/2017. ISSN i806-9584.

GUILHOTO, Joaquin ; SILVEIRA, Fernando ; ICHIARA, Silvio ; AZZONI, Carlos. 2006. A importância do agronegócio familiar no Brasil. Revista de Economia e Sociologia Rural. V. 44. N. 3. Brasília, DF: Sociedade Brasileira de Economia e Sociologia Rural. PERÍODO (jul. - set.) ISSN o103-2003.

LAKATOS, Eva Maria; MARCONI, Marina de Andrade. 2006. Fundamentos de 1397 metodologia científica. 6. ed. São Paulo: Atlas.

LEI MUNICIPAL 159I/20II. Dá nova redação ao programa leite nota to e institui bônus de incentivo a inseminação artificial do rebanho leiteiro; concede bônus de incentivo a comercialização formal de leite e dá outras previdências. Doutor Mauricio Cardoso. Disponível em: www.pdrmcard.com.br/site/conteudos/405programas. Acesso em: II/II/2017

LOVATO, Adalberto. 2013. Metodologia da pesquisa. Três de Maio: SETREM. ISBN 97885-99020-05-0.

MARCONI, Marina de Andrade; LAKATOS, Eva Maria. 2013. Metodologia do trabalho científico: procedimentos básicos, pesquisa bibliográfica, projeto e relatório, publicações e trabalhos científicos. 7. ed. São Paulo: Atlas. ISBN 978-85-22448-78-4.

NORO, Cristian Rafael; STEIN, Darlei; KRETSCHMER, Felipe Gustavo; KRETSCHMER, Rafael Henrique. 2017. Análise da execução do programa "leite nota ro" do município de Doutor Maurício Cardoso/RS. In: XV Salão de Pesquisa SETREM, 2017. 
Três de Maio: SETREM. [acessado em 27/08/2017]. Disponível em: https://portal.setrem.com.br/files/downloads/32215-anais-saps-2017.pdf

Prefeitura Municipal de Horizontina. 2019. Leis Municipais. [Online]. Acessado em: I5/II/2019. Disponível em: https://leismunicipais.com.br/camara/rs/horizontina. SOUTO, Thales Silveira; BEZZI, Meri Lourdes. 2017. O setor pecuário de leite bovino no brasil e as políticas públicas: o município de Ituiutaba/MG como foco de análise. In: Encontro Nacional da ANPEGE, XII. Porto Alegre, RS: ANPEGE. ISSN 2175-8875.

SOUZA, Osmar Tomaz. 1999. O setor leiteiro: políticas, competitividade e impactos da liberalização comercial nos anos noventa. Dissertação (Mestrado em Economia Rural). Porto Alegre, RS: Universidade Federal do Rio Grande do Sul.

TELlES, Tiago Santos; TANAKA, Julia Midori Ueda; PELlINI, Tiago. 2008. Agricultura familiar: pecuária leiteira como locus das políticas públicas paranaenses. 